\title{
EDITORIAL
}

\section{A GRANDE COLHEITA DE DADOS E A TEORIA DO DIREITO NO BRASIL}

\author{
THE GREAT DATA HARVEST AND THE THEORY OF LAW IN BRAZIL
}

Nada justifica disfarçar algo que, de fato, já aconteceu. Uma grande colheita de dados humanos ocorreu durante as últimas 2 décadas. Em termos de revolução, há semelhanças dessa com a outra, a grande revolução agrícola de 12.000 anos atrás. Mas agora é uma colheita de dados humanos. E ela nutre a revolução tecnológica que está mudando os padrões de competitividade industrial, de funcionalidades do corpo humano, de modo de vida, de comunicação com os outros e, sobretudo, de fazer ciência, de ensinar e de aprender. Como a outra, essa grande colheita é um fato de repercussão global. Seus efeitos, no entanto, ainda são pouco explorados pela teoria do direito de países em desenvolvimento.

A intensidade da mudança gerada pela grande colheita de dados não permite classificá-la como uma nova onda de aperfeiçoamentos tecnológicos. Objetos com funcionalidades completamente novas foram criados e a partir deles emergiram inéditos mercados de informação e de comunicação. Necessidades desconhecidas foram estabelecidas e uma nova indústria de bens e de formas de prestação de serviços se instalou. Aos poucos nos acostumamos a pensar que a explosão de informações veio para servir e para melhorar a vida humana. Em certa medida isso é verdade. Mas a grande disrupção tecnológica seria impossível se as novas tecnologias não pudessem, elas também, servir-se de seres humanos, ou melhor, de seus dados.

Já não há mais dúvidas de que a atual revolução da ciência convertida em tecnologia da informação por centros avançados, como MIT ou de empresas privadas, como a Alphabet Inc. (que inclui Google, Youtube, Vevo, Gmail, Android, Life Science, Calico, Waymo, Deep Mind, X-Lab), a HP, Adobe, eBay, Intel, a VISA, o Facebook (que inclui WhatsApp, Instagram) o Uber, Netflix, Tesla, Cisco e a Apple, todos ícones do vale do Silício, além de Amazon, da Microsoft (que inclui a Nokia Mobile Phones) e do Twitter, não há dúvidas de que todos estão induzindo a nova corrida pela produtividade econômica apoiando-se numa colossal colheita de dados humanos.

Mecanismos de mercado combinados com fundos públicos suavizaram a imagem da grande colheita. Não parece abusiva. A revolução da tecnologia bateu às portas por via das prateleiras de supermercados e de lojas especializadas. Suavemente entrou no dia a dia da produção das empresas privadas, da vida doméstica, dos serviços públicos e do aparelho de justiça. Sempre pelas premissas da oferta e da procura, e cheirando a novo. Em nome da inovação.

\footnotetext{
Email: strapazzon.carlos.luiz@gmail.com
} 
Smart coisas e redes sociais já se adaptaram ao cotidiano como se fossem parte do corpo ou das famílias: membros que faltavam. Agora, com mais pesquisa e mais dados humanos disponíveis, objetos estão ficando ainda mais funcionais. Mais smarts. $\bigcirc$ momento atual é de radicalização: intensificar a integração das smart coisas, com apoio na Inteligência Artificial, aos conhecimentos da biometria, biologia e robótica. Essa integração já existia, mas era aplicada com mais ênfase ao campo da saúde. Ali essa integração foi crucial para a segurança e precisão de diagnósticos e de procedimentos cirúrgicos. Dados biométricos integrados a microscópios associados a superprocessadores de gigantescas bases de dados, favoreceram o desenvolvimento da pesquisa de doenças complexas, como o câncer. Além disso, abriram caminho para a produção de objetos que demonstraram sua eficácia na modificação do corpo, pela recuperação de funcionalidades de pessoas com impedimentos motores, visuais e auditivos.

Os desenvolvimentos da biometria, no entanto, saltaram do campo da saúde para todos os objetos tecnológicos de uso comum. E as potencialidades desses objetos para coletar dados humanos foram amplificadas. Não é à toa que os investimentos nesse setor saltaram de modo extraordinário. Mais do que tecnologia aperfeiçoada, a integração da biometria a objetos tecnológicos é indicativo de que essa revolução quer escanear a vida, particularmente, a humana. Mas isso só é possível se houver dados humanos disponíveis para serem analisados.

Além das palavras digitadas em buscadores de informações na internet, seres humanos estão fornecendo impressões digitais, voz, sons, imagens faciais, expressões de humor, preferências, modos de olhar o mundo. Diariamente, muitas dezenas de mensagens escritas ou faladas, selfs e fotografias de ambientes são capturadas por smartphones, PCs e APPs. Mais ainda, dados de transações financeiras, de localização, de relacionamentos pessoais. Todas imediatamente transferidas para bases de dados de empresas privadas e de governos. Ali formam algoritmos. E algoritmos viram produtos.

A grande colheita de dados que já aconteceu não foi democrática. Ao invés de ter sido planejada democraticamente (ou o inverso, imposta por governos autoritários), a colheita se deu por mecanismos de mercado, numa esfera microeconômica: consumidores e empresas decidiram investir em inovações baseadas em coleta e compartilhamento de dados pessoais. Objetos tecnológicos que colhem dados foram desenvolvidos por poucas empresas globais, com seus recursos próprios, é verdade. Mas em boa medida com subsídios de governos democráticos. Por outro lado, governos democráticos também passaram a coletar dados pessoais fornecidos por essas empresas e estão aprendendo com elas.

O caso mais emblemático é o dos EUA e sua política de reação ao terrorismo. A partir de 11 de setembro de 2001, a política de segurança do governo dos EUA legitimou a adoção de medidas extremamente arrojadas de quebra de privacidade em todo o planeta. O propósito é garantir confiabilidade na vigilância e na identificação de ameaças dentro e fora de seu território. A Agência Nacional de Segurança tem essa função. Para isso estruturou, e usa, seu avançado sistema de mineração de dados em escala global. Mas não faz isso sozinha. O trabalho de coleta de dados é feito pelo governo com par- 
ceiros do setor privado que controlam tecnologias ainda mais avançadas, com destaque para a Palantir, empresa protegida pela CIA e fundada por sócios da PayPal e que vende serviços de informações capazes de observar tudo e ... de prever tudo. Isso mesmo, sua especialidade não é mais vender probabilidades. É vender predições. Usando a mais sofisticada mineração de dados, a Palantir pode prever o futuro. Por isso sua lista de clientes incluiu a CIA, o FBI, a NSA, o Centro de Controle de Doenças, o Corpo de Fuzileiros Navais, a Força Aérea, o Comando de Operações Especiais, West Point e o IRS. Além desses órgãos centrais do governo, a empresa atua fortemente em Wall Street, onde oferece ferramentas analíticas para hedge funds, bancos e empresas de serviços financeiros. Um dos maiores investidores da Palantir, aliás, é a $\underline{I n-Q-T e l}$, a empresa da CIA que investe em empresas de tecnologia com o único propósito de ter acesso ao que há de mais recente em termos de tecnologia da informação. A metáfora do Jornal The Guardian (30.07.2017) é que a Palantir atua como uma espécie de Olho de Sauron, da obra fictícia de JRR Tolkien. Como a Pedra de Saruman, essa empresa detém uma tecnologia que tudo vê, inclusive crimes ainda não praticados. É um passo além no projeto Predictive Policing.

Outro caso importante que vem de país democrático é a Índia. Ali está em andamento a política de Unificação de Identidade Pessoal, denominada Aadhaar. A Índia está coletando dados biométricos e geográficos de cada um de seus residentes, estimados em 1,3 bilhão de indivíduos. Com isso cada indiano terá um número único de identificação de 12 dígitos (a UID). Se tiver essa identidade poderá praticar qualquer ato da vida civil e ter acesso a direitos sociais. Se não tiver, está fora. Esse, ao menos, era o objetivo inicial do governo, mas em junho de 2017 a Suprema Corte da Índia analisou o caso e decidiu que o recebimento de direitos sociais, ao menos, não poderia ser condicionado ao registro no Aadhaar. A decisão relativizou o ímpeto do governo em obrigar todos a estarem no sistema. De todo modo, o Ministério da Tecnologia da Informação foi autorizado a manter os dados coletados, ou seja, nome, data de nascimento, sexo, endereço, nome do pai, número de telefone celular e o número de identidade e e-mail. Além disso, fotografar o rosto, colher 10 impressões digitais e também escanear os olhos de cada indiano para, daí para sempre, ter reconhecimento de íris de cada residente da Índia. Trata-se do maior sistema de identificação biométrica do mundo. Em agosto de 2017, 1.177.233.126 indianos já estavam com seus dados pessoais no novo sistema.

A capacidade da Inteligência Artificial (IA) de atuar nesses dados já colhidos, e noutros mais que seguem sendo colhidos a cada segundo, terá efeitos ainda muito pouco estudados pela teoria do direito. No campo do direito à saúde, para voltar ao campo mencionado no inicio, espera-se que milhões de registros clínicos de pacientes possam ser analisados simultaneamente e que a IA ofereça caminhos para diagnósticos e tratamentos mais personalizados. A descoberta de conexões entre características genéticas e fenotípicas também será possível pois se espera que o sequenciamento completo do genoma, ao menos uma vez na vida, seja algo normal. Mas esse nível de inteligência de megadados colhidos sem deliberação democrática também pode levar ao surgimento de subpopulações autodefinidas, cada uma administrada por um ecossistema de profissionais com sistemas de recomendação e de monitoramento automatizados. Esses desenvolvimentos têm o potencial de 
transformar radicalmente os cuidados de saúde, não há dúvida. Mas podem mudar também todas as formas conhecidas de discriminação, de socialização e de controle.

Paradoxal, diante disso, é admitir que a pesquisa em direito não está familiarizada com análise de dados. Se, por um lado, a iniciativa do Ministério da Justiça "Pensando o Direito" estimulou o desenvolvimento de pesquisas com dados empíricos nos 52 projetos aprovados, ainda há muita descrença em relação ao modo como a pesquisa em direito procede para gerar um resultado, mesmo que métodos de análise de dados sejam utilizadas.

Nossa experiência editorial acumulada nesses anos, somada ao acompanhamento das discussões sobre ciência do direito no Brasil fazem pensar, como hipótese, que se colocados na balança os métodos preferidos pelos pesquisadores do direito no Brasil, haverá um predomínio da abordagem tradicional de análise lógica e sistemática do direito positivo, com formulação de hipóteses de interpretação lógica a partir de alguma discussão com jurisprudência selecionada. Em segundo lugar virá uma abordagem de crítica humanística, seja pelo enfoque da filosofia da justiça, da linguagem, da retórica e da argumentação, talvez da filosofia critica marxista, da filosofia feminista ou da filosofia hermenêutica, ou ainda, da crítica histórica. Só em terceiro lugar, com pouca relevância, a pesquisa da funcionalidade das instituições vigentes com base em dados disponíveis ou em novas pesquisas de dados.

Se essa hipótese estiver correta, o hiato que existe entre a capacidade analítica dos atuais métodos de pesquisa e de elaboração de teoria do direito no Brasil e o modo como outros campos do saber já navegam em bases de dados é abissal.

E se essa hipótese estiver correta, e parece que está, então Programas de Mestrado e de Doutorado, e toda a comunidade científica que pesquisa e que se preocupa com o desenvolvimento, com a democracia e com as instituições de justiça no Brasil deveriam agir para fazer novas perguntas e encontrar as respostas que precisamos para lidar com esse ambiente de abundância de dados e de tantas incertezas quanto ao seu uso por governos e empresas. 